\title{
Why I Write Academic Blogs
}

\author{
Dilshan Pieris \\ Faculty of Health Sciences, McMaster University, Ontario, Canada
}

ABSTRACT

Peer-reviewed academic publications are considered a gold standard for sharing scholarly work. However, this traditional method is not without challenges; peer-reviewed journals take several months to publish articles and often limit accessibility through scientific rhetoric and restricting full-texts to those with paid memberships. Based on the literature and my personal experiences, I explain how academic blogging can help overcome these barriers, while introducing other challenges: smaller word counts, feedback from less reviewers, and potential for misinterpretation. Overall, I urge others in academia to consider including blogs in their repertoire for disseminating knowledge rather than aiming solely for peer-reviewed articles.

\section{RÉSUMÉ}

Les publications scolaires révisées par les pairs sont considérées comme l'étalon d'or pour le partage d'œuvres universitaires. Par contre, cette méthode traditionnelle n'est pas sans défis ; les journaux révisés par les pairs prennent plusieurs mois pour publier des articles et limitent souvent l'accessibilité en exigeant une rhétorique scientifique et une adhésion payée pour les articles complets. Basé sur la littérature et sur mes expériences personnelles, j'explique comment tenir un blogue scolaire peut aider à surmonter ces barrières en introduisant d'autres défis : un nombre de mots plus petit, la rétroaction venant de peu de critiques, et le potentiel pour l'interprétation erronée. Dans l'ensemble, j'encourage les autres dans les domain es scolaires à considérer d'inclure les blogues dans leur répertoire de partage de connaissances, au lieu de viser seulement pour des articles révisés par les pairs.

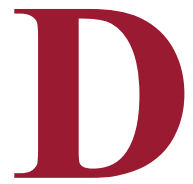
uring my post-secondary academic career, I have become familiar with the high regard held for peer-reviewed publications. Not only are they a valuable tool for scholars in all disciplines to share their work with peers and colleagues, but they also serve as a testament to one's scholarly endeavours. As a student, I am always impressed when I encounter individuals who have published many articles throughout their academic careers. Admittedly, I have also experienced imposter syndrome from witnessing these achievements, feeling as though I have fallen short for not meeting this implicit expectation to publish. As a result, publishing peer-reviewed articles has been a goal of mine for many years. However, I quickly learned that publishing in scholarly journals is not without issues, namely slow turnaround times between submission and publication, as well as limitations to accessibility with respect to physically accessing full-text articles and engaging diverse groups of readers. Consequently, I turned to academic blogging as an alternative medium through which I could disseminate my work in addition to the traditional peer-reviewed route. By supplementing my personal experiences with evidence from the literature, I hope to discuss turnaround time and accessibility as they pertain to both peer-reviewed journals and academic blogs. The aim of this commentary is to explain why I view the latter as essential, while also presenting benefits and drawbacks of both mediums so that readers are empowered to decide what they prefer.

\section{TURNAROUND TIME}

One issue I have encountered in the world of peer-review is the slow turnaround time. For example, some papers I have submitted have taken several months to be published-this is not uncommon. In an analysis of papers published in the PubMed database between 1980 (in 4,353 journals) and 2015 (in 9,045 journals), a median turnaround time of about 100 days between submission and decision was found (1). However, this can sometimes take even longer; one manuscript I have previously submitted has been under review for almost a year. One reason for these long turnaround times is the high volume of submissions (1). For instance, the number of yearly submissions to PLoS ONE was about 30,000 in 2014; Academic Medicine, a prominent medical education journal, receives about 1,500 submissions each year $(1,2)$. Naturally, finding multiple reviewers for this many articles is particularly difficult, resulting in further increases to submission-decision turnaround time (1). Furthermore, receiving this decision

Keywords: Publication; Blogging; Peer-review; Scholarship; Knowledge; Research 
is not the end of the process; acceptances typically include major and minor revisions for authors to incorporate in a resubmission that must be reviewed once again. From a revisions perspective, increased turnaround time can be beneficial because it enables multiple reviewers with relevant knowledge and experience to appraise the submission and offer constructive feedback, ultimately improving the quality of the work. However, such delays in disseminating research and scholarship can also serve as a rate-limiting step for advancing the field and educating others about our work. For time-sensitive publications, like systematic reviews, slow turnaround times can even increase the risk of findings becoming outdated by the time they are published. In fact, the Cochrane Handbook for Systematic Reviews of Interventions (Version 5.1.0) states that literature searches should be updated every six months (3).

Contrary to scholarly journals, academic blogs publish articles a lot more quickly. One reason for their faster turnaround times are that blogs typically publish shorter articles as compared to traditional journal articles. For instance, KevinMD.com, a prominent healthcare blog, has a maximum word count of 1,000 words; articles of this length can be read more quickly, allowing for a submission-decision turnaround time of about 10 days, with subsequent publication occurring in 1-3 weeks (4). From my personal experience, these timelines were even shorter. Additionally, the Canadian Medical Association Journal (CMAJ) also has a 1000-word maximum and a quick submission-decision turnaround time, accepting one of my pieces within 5 days of submission and publishing it 11 days later (5). However, while smaller word counts allow articles to be more efficiently reviewed, authors must sometimes sacrifice depth of content in order to remain within these limits. Another reason that blogs have quicker turnaround times is that they do not undergo a thorough peer-review process. Though this allows blog submissions to be appraised more quickly, it also limits authors to feedback from one reviewer instead of receiving comments from multiple reviewers. Nonetheless, submissions to KevinMD.com, CMAJ Blogs, and many other blogs available online are still appraised by individuals with relevant knowledge and experience while also publishing articles promptly. This allows for more content to be produced in a shorter period of time, making academic blogging more efficient than the traditional route of publication (6).

\section{ACCESSIBILITY}

Another issue I have encountered with peer-reviewed publication is regarding accessibility. While some journals are openly accessible, many require paid subscriptions to access full-text articles. As a result, those without such memberships cannot read these journals, which hinders individuals from engaging with the research detailed within them. Seeing the value in such engagement, I aimed for my peer-reviewed articles to be publicly accessible; however, the 3,000 USD fee for open access publishing in many journals severely limited my ability to do so (6). Even when I was able to publish articles that were accessible in full, they were written in scientific language-as per the journals' specifications-that caters to scholars already in the field. On the one hand, this is helpful because these scholars are most directly immersed in the field, making them well-positioned to create meaningful change based on the contents of these publications. However, tailoring peer-reviewed articles exclusively to researchers in the field also limited my ability to engage individuals from diverse academic backgrounds who may have had useful insights to offer but were unable to navigate my discipline-specific terminology and phrasing. Moreover, such scientific rhetoric hinders knowledge translation for the general public, unfairly excluding them from consuming certain knowledge simply because they are not from the field wherein that knowledge was produced. This is especially concerning when the content has potential to affect members of the public, such as research about cutting-edge treatments or how the next generation of health professionals are being trained. While reducing or eliminating open access fees may not be feasible for journals not receiving subsidies to cover publication costs, accessibility to journal articles can be partially improved by encouraging authors to simplify their rhetoric.

Authors can also improve accessibility to their content by disseminating it in academic blogs in addition to peerreviewed journals (6). Most academic blogs are freely accessed by the general public and do not ask contributing authors to pay open access fees. This not only enables those with an interest in the blog to engage with its content, but also encourages authors to submit articles-myself included. Moreover, academic blogs typically publish articles written in casual language that is more engaging than the scientific rhetoric in many traditional journals, thereby improving readability for consumers of diverse backgrounds and levels of education (6). Wanting to engage the general public and individuals from other fields, this was appealing to me. Through my submissions to KevinMD.com and CMAJ, for instance, I was able to generate rich discussion amongst individuals outside 
of the medical education field about physician empathy and medical school admissions. Another benefit of open access and conversational tone is that they allow blogs to grow their following substantially, giving their articles a larger reach than journals requiring paid subscriptions and scientific rhetoric. For example, KevinMD.com receives about 3 million views per month, and the Harvard Macy Institute blog receives an average of about 1500 hits on each post $(4,7)$. One potential drawback of academic blogs being openly accessible is that given their greater diversity in readership as compared to peer-reviewed journals articles, they may be more susceptible to misinterpretation if not written clearly. Nevertheless, the ability for academic blogs to disseminate information to such large audiences is a powerful tool; in addition to writing for peer-reviewed journals, scholars should leverage academic blogs to increase their readership and discussion about their work. These conversations are valuable for generating awareness, perspectives, and even solutions about the topic covered in the articles, which ultimately help to advance the field.

\section{CONCLUSION}

Overall, peer-reviewed publications are undoubtedly an integral part of academia, and I am not suggesting that we devalue them. Instead, I hope that others may consider academic blogging as a complementary-not mutually exclusive-option to their traditional peer-reviewed journal publications. In this article, I explained my reasons for including academic blogging to my repertoire, while also providing benefits and limitations for both mediums with respect to issues of turnaround time and accessibility, with literature and personal experiences supporting my claims. With this information, readers can weigh these considerations and arrive at their own conclusions regarding academic blogs. Nonetheless, whether it be through peer-reviewed journals, academic blogging, or a combination of both mediums, we have a social responsibility as researchers, scholars, and aspiring physicians, to progress our respective fields, and society as a whole, through education and knowledge translation.

\section{REFERENCES}

1. Powell K. Does it take too long to publish research?. Nature News. 2016 Feb;530(7589):148-51.

2. Academic Medicine. Frequently Asked Questions for Authors [Internet]. journals.Iww.com/academicmedicine; [cited 11 December 2018]. Available from: https://journals.lww.com/academicmedicine/Documents/Academic\%20Medicine\%20Frequently\%20Asked\%20Questions\%20for\%20 Authors.pdf

3. Higgins J, Green S (editors). Cochrane Handbook for Systematic Reviews of Interventions Version 5.1.0 [updated March 2011]. The Cochrane Col- laboration; 2011. Available from http://handbook.cochrane.org.

4. Pho K. Be heard on social media's leading physician voice [Internet]. KevinMD.com; n.d. [cited 2018 Oct 30]. Available from: https://www.kevinmd. com/blog/heard-social-medias-leading-physician-voice.

5. CMAJ Blogs. About Us [Internet]. cmajblogs.com; n.d. [cited 2018 Oct 30]. Available from: https://cmajblogs.com/about/.

6. Barton CJ, Merolli MA. It is time to replace publish or perish with get visible or vanish: opportunities where digital and social media can reshape knowledge translation. Br J Sports Med. 2017 Nov;bjsports-2017.

7. Harvard Macy Institute. Harvard Macy Community Blog [Internet]. harvardmacy.org; n.d. [cited 2018 Oct 30]. Available from: https://www. harvardmacy.org/index.php/hmi-blogs.controlled trial of idebenone in Leber's hereditary optic neuropathy. Brain. 2011;134(9):2677-86. 